\title{
Reproductive health service utilization and associated factors among youths in Dilla town, Southern Ethiopia, 2017.
}

Rekiku Fikre ( $\square$ frekiku@yahoo.com )

Hawassa university

Masresha Soresa

USAID

\section{Research note}

Keywords: Reproductive health, utilization, Youth, Dilla town

Posted Date: September 12th, 2019

DOI: https://doi.org/10.21203/rs.2.14381/v1

License: () (7) This work is licensed under a Creative Commons Attribution 4.0 International License. Read Full License 


\section{Abstract}

Objective

Youth make significant proportion of the population in Ethiopian. They have unique health related needs and wellbeing as they transition from childhood to adulthood. As a result they are involved to a variety of risky sexual behavior and face a lot of challenges. However, utilization of reproductive health service among youth is still low. Therefore the objective of this study was assessing reproductive health service utilization and associated factors among youths in Dilla town, Southern Ethiopia, 2017.

Results

Prevalence of reproductive health service utilization among youth was $34 \%$ (95\% Cl: 17.2-29.1). Predicator for utilization of reproductive health service among youth were, peer educators [AOR $=3.12,95 \% \mathrm{Cl}(5.76,8.3)$ ] youth club $[\mathrm{AOR}=2.78,95 \% \mathrm{Cl}(3.67,9.11)]$, school min-media $[\mathrm{AOR}=1.79,95 \% \mathrm{Cl}(1.00,3.19)$ and approach of providers $[A O R=4.11,95 \% \mathrm{Cl}(5.54,11.23)]$ were associated with utilization of reproductive health service.

\section{Introduction}

Young population accounts 1.8 billion which is $24.3 \%$ of the global population and 1.4 billion young were in developing countries. Youth is Period of transition and experimentation, involves distinct physiological, psychological, cognitive, social \& economic changes. They involved in risky sexual behavior such as unprotected sex, substance abuse \& dangerous recreational activities, can be caused by, Curiosity Peer pressure and Sexual maturation. However on the presence of such reality reproductive health issue of adolescents \& youth were neglected by community and health care providers [1]. Accessing RH service for youth is standardizing the quality of services with the characteristics of accessible, acceptable, comprehensive, appropriate, equitable, effective and efficient and an approach which brings together the qualities that young people demand, with the high standards that have to be achieved in the best public services. However the culture of youth to access RH service was limited as result they are prone for different problems, such as teenage pregnancy, unsafe abortion and sexually transmitted infections (STI) [2]. According to world health organization Up to $60 \%$ of new infections occur among 15-24 yrs in developing countries and the vast majority of adolescents in low income country face unplanned pregnancy [3\&4].

Youth are single largest group in the country, accounts for $42 \%$ of the total population. In recognition of such realities the national youth and educational policies focused on how to reach young people in Ethiopia with relevant services. Yet, characteristically there is wide range of variation in terms of age, sex, schooling, residence and needs posing opportunities and challenges to programs designed for young people [5].

Majority of youth lack information and they are low trend of utilizing reproductive health service due to, fear of being judged by service provider, lack of privacy, feeling that services are intended for married people and unaware of service locations or services offered [6\&7].

Ethiopia government has developed a 10-year National Adolescent and Youth Reproductive Health Strategy. However, they have focused on the clinical aspects but the non-clinical aspects are poorly addressed so, ensuring effective interventions during this period protect public health investments. As a result, utilization of reproductive health service has become a primary concern of Sexual and Reproductive Health rights in the country [8\&9].

Studies show that adolescents and youth in Ethiopia are prone to various forms of RH problems including: early marriage, unplanned pregnancies, and sexually transmitted infections including HIV. Factors associated with utilization of reproductive health service were, lack of information, providers approach, facility readiness and financial dependency [10\&11].

Current studies focused on higher learning institute students revealed that one third of university students have had sexual experience. Of these, nearly two third were found to have sexual experience already before joining the university which evidences that RH problems manifest early on and calls for interventions at early stage [12].

Hence, evidence on utilization of reproductive health service is very limited in Ethiopia. Therefore, this study aimed to asses'reproductive health service utilization and associated factors among youths in Dilla town, Southern Ethiopia, 2017.

\section{Methods}

Study design, study population and sampling procedure

A community based cross-section study design was carried out from June 1-30/2017 among youth in Dilla town, Gedeo zone, southern Ethiopia. Dilla town is located $394 \mathrm{~km}$ from South of Addis Ababa which is the capital city of Ethiopia. According to 2007 census the population of the town was estimated to be 101,304 and 43, 463 were youth population [13]. Hospital found in the city is: one governmental teaching hospital. The city had two health centers and one maristope clinic. The study units were youths living in selected kebele for at least six months were included for the study.Sample size was determined byusing single population proportion formula with the following assumption: $95 \%$ level of confidence $(Z= \pm 1.96)$, Margin of error ( $d=5 \%$ ), none response rate $=10 \%$, Prevalence $=50 \%$, considering design effect 2and sample size for quantitative analysis was 845 .

A multistage sampling procedure was used to select e study participants from youths aged 15-24 years and living in the town. The town was stratified into eight strata, using the existing division of the district. From each district, one kebele was selected by a lottery method. The study samples were proportionally allocated to the youths' population size of each kebele. In order to develop a sampling frame, a baseline enumeration of the total households in each kebele was conducted. Then, a simple random sampling technique was used to select the eligible households from the sampling frame. 
The data was collected face to face using structured and pretested questionnaire interviews. The questionnaire was prepared by reviewing existing literatures $[14,15]$ which consist of socio-demographic characteristics, knowledge about and attitude towards RH service, and level of utilization and the factors associated with RH service. Three (03) nurses who have YFS training were recruited and training was given for 02 days on the objective, relevance of the study, confidentiality of information, respondent rights, informed consent, and technique of interview; 02 health professional who have 1st degree (BSC midwife) were trained and supervise the data collection. The qualitative data was collected using semi-structured interview guides designed for RH service providers and the youth themselves. FGDs and in-depth interview carried in Amharic until the point of saturation was reached. The discussions were tape recorded with permission from the participants. The transcribed data were compared with the notes taken during discussion.

Data analysis

Data entry was done using EPI Info 3.5.1 and exported to SPSS version 20.0 software for analysis. The presence of association between independent and dependent variables was determined using odds ratio with $95 \%$ confidence interval by applying logistic regression model.

The qualitative data were transcribed and typed in word, and translated back into English by the investigators and analyzed using thematic analysis. The main thematic areas from the qualitative data were identified, coded, and significant quotes were also noted in the text.

\section{Result}

Socio-demographic characteristic of respondent

A total of 845 youth were involved in this study and provided a response rate of $100 \%$. The age of participants ranged from $15-24$. The mean age (in years) of the studypopulation was $17.02 \pm 5.45$ years.Gedeo was a dominant ethnic group, which accounted $36.9 \%(n=312)$ See table1.

Knowledge and attitude towards reproductive health services

Majority 768 (90.8\%) were understood that reproductive health service is important and most of the youth had information about reproductive health service from peer educators 204 (24.1), youth club 188 (22.2\%) and school min-media 213(25.2\%). Abortion (31.3\%), unintended pregnancy (28.7\%), unsafe sexual practice (17.6\%), and STIs/HIV/AIDS (22.4\%) were the major RH problems described by youths see fig 1.The reproductive health service known by youths were family planning (36.7\%), abortion care (26.4\%) and STIs including HIV/AIDS (31.4\%) and health education (5.5\%). 186(22 \%) were knowledgeable about reproductive health service given at the health institutions. Majority of the respondent had positive attitude. Response from the youths that using condom (32.4\%) abstaining from sex (40.1\% \%) followed by faithfulness to partner (27.5\%) were the major modes of preventing HIV/AIDS reported by the youth.

\section{Utilization of reproductive health services}

The prevalence of reproductive health service utilization in Dilla town was $34 \%$. During focu group discution youth described reasons why they visit reproductive health service and they described for support of family member for health care service, for other medical service.

$43.7 \%$ of youth were visits reproductive health service for the first time and (4.6\% \%) got counseling service, (14.3\%) were for contraceptive services, (3.8 \%) were for pregnancy related servicesand post abortion careaccounts $(1.1 \%$.).

Factors associated with utilization of reproductive health services

Peer educator $[\mathrm{AOR}=3.12,95 \% \mathrm{Cl}(5.76,8.3)]$, school min-media $[\mathrm{AOR}=1.79,95 \% \mathrm{Cl}(1.00,3.19)]$, youth club $[\mathrm{AOR}=2.78,95 \% \mathrm{Cl}(3.67,9.11)]$ and approach of health care provider $[A O R=4.11,95 \% \mathrm{Cl}(5.54,11.23)]$ as source of information were factors associated with reproductive health serviceutilization Table 2.

During the time of discussion, Facility readiness was repeatedly raised as a factor that prevented the youth from acquiring essential RH services. A 19- year male discussant said "while you seek reproductive health service and moved to health facilities, the service were not provided in separate room and we lost our confident and privacy so that we become ashamed of discussing our problem."

A 17 year- old female discussant who visited the facility for abortion service described "while at the time of my visit the provider asked me how can I get pregnant and I told him that from my boyfriend and providers told me it is sin so that I ashamed and lost confident trough out the process. "other

Moreover, an 18 years old male discussant indicated about setup of the facility "when he visits the health facilities the environment was not conducive so he was afraid of sawing community member and left the facilities before getting the service."

At the time of, in-depth interview they were asked about provision of the service, the respondent from public institutions explained that there is no specifically designed RH services room for the youth in their institutions as well RH services are offered for youths without giving them aspartate room so that they are treating them as adult clients.

Additionally, the respondents of the in-depth interview were asked whether they have been given training on RH and approaching the youths. The respondents reported that they have taken such trainings and are confident that they could respond to the needs of the youth. 
Provider from the government institution said, ".... I have obtained trainingon how to provide the service, But I am assigned in another unit and am working in $\mathrm{RH}$ clinic as aback up so that which is not appropriate for me providing the service per standard."

\section{Discussion}

Reproductive health is a major public problem in developing country and this problem increase its magnitude which brings a major public impact.The aim of this study was assessing reproductive health service utilization and associated factors among youths in Dilla town, Gedeo zone SNNP 2017.

The prevalence reproductive service utilization in Dilla town was 34\%. This result was inconsistence with study conducted in Bahir Dare 32.2\% [16], in Addis

Ababa 29\% [17] and in metekel 21.5\% [18], and lower than study conducted in Harar town, east Ethiopia, and west harergea Ethiopia which is $63.8 \%$ and $42.1 \%$ respectively [19\&20]. This difference might be due to different in study setting and time.

On this study $4.6 \% \%$ got counseling service and $14.3 \%$ were for contraceptive services. This is lower than study conducted in Debre-Brehan $43,6 \%$ of youth got counseling service and $21.9 \%$ for contraceptive services [21.]This is due to different on facility readiness and approach of the providers.

Current study described most youth's visits RH services were for library and recreational services (37.2\%). This is in line with study done on Addis Ababa [17].

This study revealed (4.6\%) of youths received counseling services,this finding was lower than study conducted in Harar town, nearly $60 \%$ of the study participants received reproductive counseling, [19], similarly lower than study conducted in Kenya (38.7\%\%). This difference might be due to poor trends of RH services and due to approach of providers which is not friendly.

\section{Conclusion}

The prevalence of reproductive health services was low in Dilla town Gedeo Zone. Sources of information for RH services were influence on its utilization among the youths. The utilization of RH services was higher among the youths who received information from health care providers, friends and schools, in this study. More emphasis should be made by all relevant stakes to create to strengthening of the awareness creation strategies among the youth to increase the utilization of the services.

\section{Limitation}

This study was a subjective bias due to most outcome variable was measured by subjective report and Causality can't be confirmed because the research design is cross sectional.

\section{Declarations}

\section{Abbreviations}

AIDS . Acquired immune deficiency syndrome

AOR …….................. Adjusted odd ratio

COR …..................... Crude odds ratio

FGDS Focused group discussion

HIV .......................... Human immune virus

$\mathrm{RH}$........................ Reproductive health

Authors' contributions

$R F$ has developed the proposal, collected data, and analyzed the data.

MS approved the proposal with due editorial revisions and revised subsequent drafts of the paper for intellectual content. All authors read and approved the final manuscript.

\section{Author's information}

Rekiku Fikre: Bsc in Midwifery, M.sc in Reproductive Health and Maternity nursing, Department of Midwifery, College of Medicine and Health Sciences, Hawassa University, Ethiopia

Masresha Soresa: RN, Bsc in sociology, Master in general public health, USAID/ Primary health care project, You1ths project coordinator, Addis Ababa.

\section{Acknowledgements}

We would like to thank Dilla University and study participants. 
The authors declare that they have no competing interests.

Availability of data and materials

All data pertaining to this study is contained and presented in this document.

Consent for publication

Not applicable

Funding

The source of fund is self.

Ethical approval and consent to participate

Ethical clearance was obtained from Dilla University College of Health Science Institutional Health Research Ethics Review Committee (IHRERC). Similarly, permission was obtained for town administration. An informed written consent was obtained from each study participant and from their parents when required prior to the data collection. Confidentiality of the information was assured by making anonymous interview and using codes for the identified participants for the FGDs and In-depth interview. Moreover, during the whole process of interview, privacy was strictly maintained.

\section{References}

- World Health Organization. World Health Organization Press; Geneva, Switzerland: 2016. Health for the world's adolescents: A second chance in the second decade.

- Erulkar.A..Tekle-Ab.M,.Sme.N,.et.al..2006...Dfferental.Use.of.Adolescent.Reproductve.Health.Programs.n.Adds.Ababa,.Ethopa...J.Adol.Health.2006;38(3).

- Patton G. C., Coffey C., Sawyer S. M. Global patterns of mortality in young people: A systematic analysis of population health data. Lancet. 2009;374:881-892. [PubMed]

- Ingwersen R: Adolescent reproductive and sexual health in the developing world. 2001, Canberra Australia: Development Studies NetworkGoogle Scholar

- FDRE, Ministry of Health [MOH]. 2016. National Adolescent and Youth Health Strategy 2016-2020, Addis Ababa.

- WHO: Adolescent pregnancy -Unmet needs and undone deeds: A review of the literature and programmes: Issues in Adolescent Health and Development. 2007, Geneva: WHOGoogle Scholar

- Braeken D, Rondinelli I. Sexual and reproductive health needs of young people: matching needs with systems. Int Fed Gynecol Obstet. $2012 ; 119$ Suppl1:S60-S63. [PubMed]

- Minster of Health.(MOH)..2006-2015.National Reproductive.Health.Strategy:.2006-2015.Ethiopia.

- Govindasamy. P,kidanu. A, Banteyerga. H. 2002.. Youth. Reproductive. Health. in. Ethiopia. Calverton,.Maryland:.ORC.Macro.

- Land.C,.Gebregiorgis.Y,.Bunde.E..2005.ComprehensiveCommunityBasedAdolescentHealth.Intervention.Trial.in.Ethiopia..Baseline.Report,.2005,.Adolescent. and.Save.the.Children.USA.

- YouthNet..2004..Youth.Issues.Paper.4,.Reaching.Out.of.School.Youth.with.Reproductive.Health.and.HIV/AIDs.Information.and.Services..Arlington,.Virginia:

- Akinyi OP. Determinants of utilization of youth friendly reproductive health services among school and college youth in Thika West District, Kiambu County, Kenya. MPH thesis. 2012, Kenyatta University.

- Federal Democratic Republic of Ethiopia Population Census Commission: Summary and Statistical Report of the 2007 Population and Housing Census: Population size by age and sex, 2008. Available at: http://ecastats. uneca.org/aicmd/Portals/0/Cen2007_firstdraft.pdf. Accessed 13 July 2016.

- FDRE, Ministry of Health [MOH]. 2007. Standards on Youth Friendly RH Services. Service Delivery Guideline \& Minimum Service Delivery Package on YFRH Services.

- World Health Organization. Adolescent friendly health services: an agenda for change, 2002. Available at: http://apps.who.int/iris/bitstream/10665/ 67923/1/WHO_FCH_CAH_02.14.pdf. Accessed 13 July 2016.

- Meskrem A, Worku A, utilization of youth reproductive service and associated factors among high school students in Bahir dar Amhara region Ethiopia, Open journal of epidemiology, 2014, 4:69-75.

- Tigst.T utilization of youth reproductive service and associated factors among in Addis Ababa open journal of epidemiology 2014,4:65-75.

- Amanuel A, Asefa S, reproductive health knowlaghe and service utilization among rural Ethiopia Methikel Asia journal of Pharmacy, Nursing and medical science 2013, 01:25-37

- Ahemed A, youth reproductive health problems and service preference, asebetferi west harage, april,2014.

- Aboma M, youth friendly health service utilization and factors in Harar town, east Ethiopia, bulletin of health science January 2012 , number 4.

- Kenean G, reproductive health and associated factors among adolcents Debre Berhan town, Central Ethiopia, reproductive health journal, 2018. Number15.

\section{Tables}

Due to technical limitations, Tables $1 \& 2$ are only available for download from the Supplementary Files section.

Page 5/6 
Figures

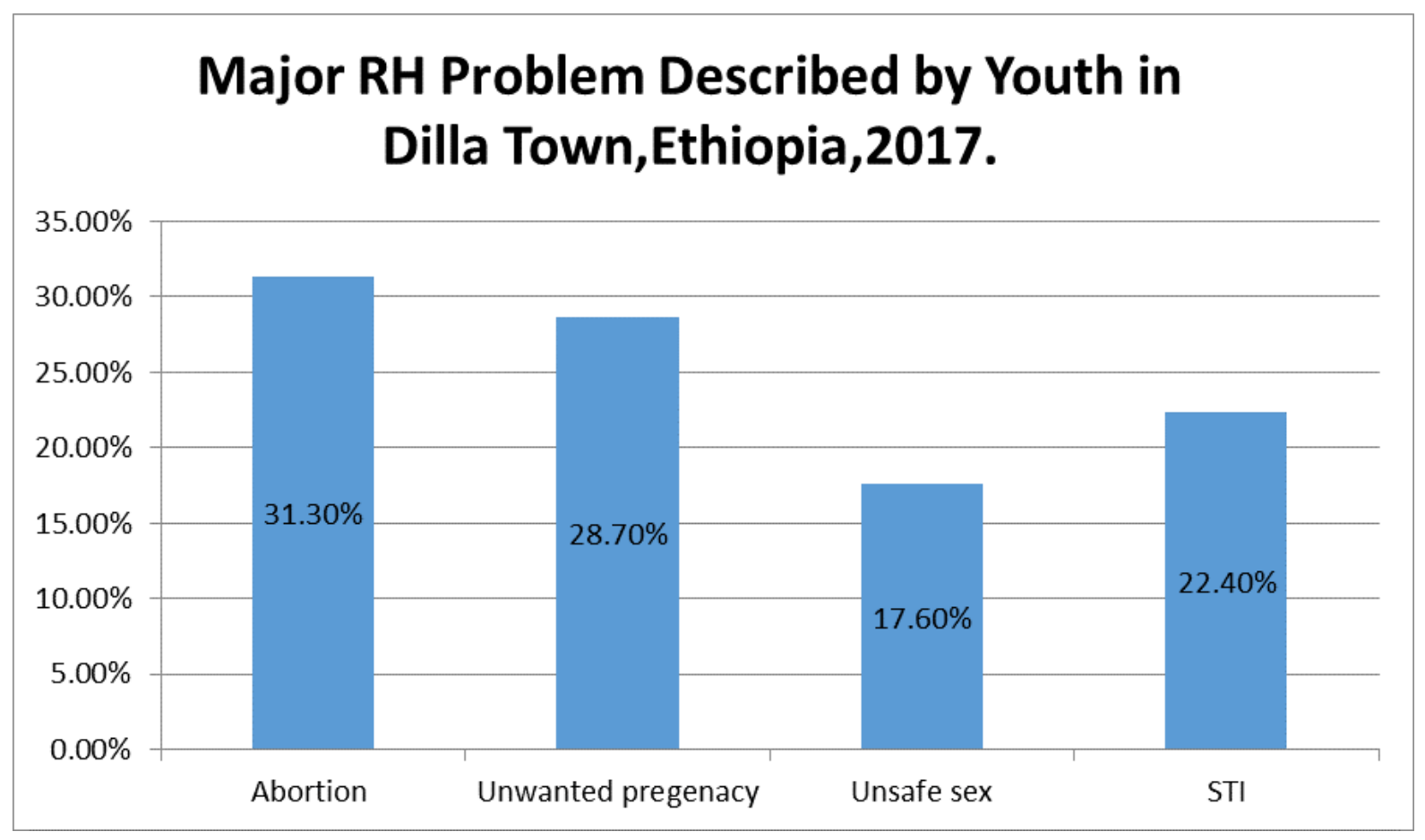

Figure 1

Major RH problem described by youth in Dilla town, Ethiopia, 2017.

\section{Supplementary Files}

This is a list of supplementary files associated with this preprint. Click to download.

- Table2.pdf

- Table1.pdf 